NASA Technical Memorandum 107205

AIAA-96-2272

\title{
An Investigation of the Compatibility of Radiation and Convection Heat Flux Measurements
}

Curt H. Liebert

Lewis Research Center

Cleveland, Ohio

Prepared for the

19th Advanced Measurement and Ground Testing Technology Conference sponsored by the American Institute of Aeronautics and Astronautics New Orleans, Louisiana, June 17-20, 1996

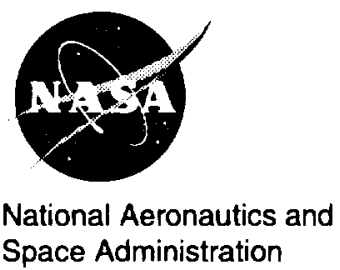





\title{
AN INVESTIGATION OF THE COMPATIBILITY OF RADIATION AND CONVECTION HEAT FLUX MEASUREMENTS
}

\author{
Curt H. Liebert \\ National Aeronautics and Space Administration \\ Lewis Research Center \\ Cleveland, Ohio 44135
}

\begin{abstract}
A method for determining time-resolved absorbed surface heat flux and surface temperature in radiation and convection environments is described. The method is useful for verification of aerodynamic, heat transfer and durability models. A practical heat flux gage fabrication procedure and a simple one-dimensional inverse heat conduction model and calculation procedure are incorporated in this method. The model provides an estimate of the temperature and heat flux gradient in the direction of heat transfer through the gage. This paper discusses several successful time-resolved tests of this method in hostile convective heating and cooling environments.
\end{abstract}

\section{Introduction}

The objective of this paper is to describe continuing efforts to develop methods for determining time-resolved heat flux and temperature. Rocket engine research initiated in the $1960^{\prime} \mathrm{s}^{1-3}$ demonstrated that seams formed during the mounting of heat flux gages can adversely effect the accuracy of the heat flux measurement. In those days, a common procedure for installing heat flux gages consisted of press-fitting cylindrical plugs into holes machined into rocket engine combustion chambers and nozzles. Temperatures were measured along the length of the plugs with wire thermocouples. Heat flux was estimated using the temperature data along with inverse heat conduction analysis. After operating the engines for a while, hot spots or temperature disruptions occurred at the seam or line of junction between the plug and nozzle material. These hot spots weakened the material causing cracks, ridges and grooves which distorted the surface profile. When this happened, the thermocouple signals were so noisy that an accurate heat flux determination could not be made. Eventually, the thermocouples were destroyed.
More recently, it became necessary to more thoroughly characterize hot gas boundary layer environments on the surfaces of stationary airfoils located in a turbine blade tester (TBT). This ground-based tester is used to simulate the hostile environment of turbines driving space shuttle main engine (SSME) turbopumps. ${ }^{4}$ Clearly, the method of press-fitting thermocoupled cylinders into materials is not satisfactory. Thus new designs for machining the cylinders into gage body materials were devised. ${ }^{5-6}$ An arc lamp facility for determining the durability and accuracy of these plug-type gages was also designed and built. Continuous radiative transient and steady-state surface heat flux values of about 0.1 to $6 \mathrm{MW} / \mathrm{m}^{2}$ can be obtained in the arc lamp facility. At these heat flux levels, specimen temperatures range from 100 to $2000 \mathrm{~K}$. The facility is used for design validation, calibration, and durability testing of sensors at fast temperature transient and steady-state conditions. The transient temperatures and heat fluxes generated by the lamp resemble those found in engine and facility startup and shutdown conditions. Material cracking and other durability problems are caused by such transients.

This report describes the experience gained when these miniature plug-type heat flux gages are tested in widely varying thermal environments. Measurements were performed in a subsonic turbine blade tester located at NASA George C. Marshall Space Flight Center, in a hypersonic arc jet facility located at NASA Ames Research Center and in an arc lamp at NASA Lewis Research Center. Also included in this report is a general one-dimensional inverse heat conduction model which is used for estimating absorbed surface heat flux on the surfaces of the miniature plug-type heat flux gages. ${ }^{7}$ When applicable, the results were spot-checked with a second, less general, semiinfinite, constant property heat conduction model. ${ }^{8}$ 


\section{Inverse Heat Conduction Model}

A typical miniature plug-type heat flux gage is shown in Figs. 1 and 2. This design is called herein a "dual active surface heat flux gage." As shown in Fig. 1, the back surface of the gage is cooled. An adjustment to the design (not shown) provides a thermal insulating air space between the back of the post and the cover. This augmented design is called herein a "single active surface heat flux gage." For both of these gage designs, internal transient and steady temperature measurements are obtained with small wire thermocouples spot-welded to the post as shown in Figs. 1 and 2. Because the post is thermally insulated on its cylindrical side, it is assumed that there is onedimensional heat transfer along the $\mathrm{Z}$-axis. The direction of heat flow is positive when flow is from the front surface to the back surface.

A general temperature dependent, nonlinear heat conduction model for obtaining an estimate of surface heat flux and active surface temperature with both the single and dual active surface gages is discussed next. A numerical example of the calculation procedure is given the appendix of Ref. 9. Deviations from this procedure are noted herein. These newer procedures provide a faster and more accurate estimation of heat flux. An advantage of this method is that it can not only estimate temperature and heat flux at the surface of the gage, but that it can also provide a measure of the actual temperature and heat flux distributions in the physical direction of normal heat conduction through the wall.

\section{Heat Balance}

A general (gen) conservation of energy equation for the gage shown in Figs. 1 and 2 is,

$$
\dot{\mathrm{q}}_{\text {front,gen }}=\dot{\mathrm{q}}_{\text {store }}+\dot{\mathrm{q}}_{\text {back }}, \mathrm{W} / \mathrm{m}^{2}
$$

The first quantity in Eq. (1) is called herein the gage output and corresponds to the heat flux absorbed on the front surface of the gage. The second and third quantities are the heat flux stored within the gage and the heat flux conducted out the back of the gage. Equation (1) is solved at selected times to produce a variation of surface heat flux with respect to time. The physical relationships for the quantities in Eq. (1) are now discussed.

\section{Thermoplug Temperature Gradients}

Using Fourier's law, an expression for the heat flux at the back surface of the thermoplug is

$$
\dot{q}_{\text {back }}=-\mathrm{k}\left(\frac{\partial \mathrm{T}}{\partial \mathrm{Z}}\right)_{\mathrm{Z}=\mathrm{L}}, \mathrm{W} / \mathrm{m}^{2}
$$

where $\mathrm{T}$ is temperature, $\mathrm{k}$ is thermal conductivity, $\mathrm{Z}$ is a location along the length of the thermoplug and $\mathrm{L}$ is the length of the thermoplug. As shown in Figs. 1 and 2, the thermoplug length, which extends along the $Z$-axis, equals the sum of the front wall thickness, the post length and the cover thickness.

To solve Eq. (2), four general models are used, in turn, to curve-fit a set of $\mathrm{T}$ versus thermocouple location data. These models are

$$
\left.\begin{array}{ll}
\text { Linear Fit } & y=b+m x \\
\text { Logarithmic } & y=b+m \ln x \\
\text { Fit } & \\
\text { Exponential } & y=b e^{m x} \text { or } \ln y=\ln b+m x \\
\text { Fit } & \\
\text { Power Fit } & y=b x^{m} \text { or } \ln y=\ln b+m \ln x
\end{array}\right\}
$$

For each of these four general models shown in Eq. (3), a least-squares regression code will find a correlation coefficient. The model or equation associated with the largest value of correlation coefficient is selected for calculation of the value of the derivative of the curve-fit of $T$ versus $Z$ at the back surface of the cover, where $Z=L$. Then, to obtain the heat flux at the rear of the thermoplug, this value of the derivative at $Z=L$ is multiplied by the thermal conductivity. The thermal conductivity is evaluated at the local temperature corresponding to the position $\mathrm{Z}=\mathrm{L}$. This temperature is estimated using the best fit equation of $T$ versus $Z$. This equation describes the temperature gradient in the direction of heat transfer through the gage.

The value of the temperature gradient shown in Eq. (2) is highly sensitive to values of the correlation coefficient, r. For instance, a change in $r$ from 0.980 to 0.990 can be associated with a change in back surface temperature gradient and associated heat flux value of 10 percent. Therefore it is important to evaluate all four curve fits for the highest value of correlation coefficient, which is called the best-fit curve.

\section{Front Surface Temperature}

Only the linear and exponential fits (Eq. (3)) of T versus $Z$ can be used to estimate the surface temperature. In arc lamp tests the surface temperatures estimated with these curve fits at $Z=0$ and also measured with thin film thermocouples compared within plus-or-minus 3 percent.

\section{Temperature Changes (Heat Stored)}

The quantity of heat stored is 


$$
\dot{\mathrm{q}}_{\text {store }}=\int_{0}^{\mathrm{L}}\left[\rho \mathrm{c}_{\mathrm{p}} \frac{\partial \mathrm{T}}{\partial \theta}\right] \mathrm{dZ}, \mathrm{W} / \mathrm{m}^{2}
$$

The first quantity in Eq. (4) is the heat flux associated with heat storage. On the right of the equals sign, the term in brackets is a time rate of change of energy per unit volume, where $\rho$ and $c_{p}$ are local density and specific heat of the thermoplug material and $\theta$ is time.

The partial derivative shown in Eq. (4) is evaluated by using Eq. (3) to compute a best-fit least squares equation for $T$ versus $\theta$ at a selected thermocouple location. The value of the partial derivative of the best-fit curve is then calculated at the selected time and then multiplied by the density and specific heat. This produces a value for the term in the brackets, which is the local energy density. The local energy density is then evaluated at the other thermocouple locations. Then, again using Eq. (3), a bestfitting least-squares curve is fit through the data points of energy density versus thermocouple location. The use of a best-fit curve is an improvement over the "polygon" approach described in step 6 on page 10 of the Appendix in Ref. 9. The integral of the resulting least-squares curvefit equation is then evaluated over the thermoplug length. This length extends from the front surface of the gage at $Z$ $=0$ to the back surface of the cover where $Z=L$. During steady-state conditions, Eq. (4) is zero because the value of the derivative of $T$ with respect to $\theta$ is zero.

\section{General Heat Flux Equation}

Substituting Eqs. (2) and (4) into (1) produces the following heat flux equation for the thermoplug.

$$
\dot{\mathrm{q}}_{\text {front }, \text { gen }}=\int_{0}^{\mathrm{L}}\left[\rho c_{\mathrm{p}} \frac{\partial \mathrm{T}}{\partial \theta}\right] \mathrm{dZ}+\mathrm{k}\left(\frac{\partial \mathrm{T}}{\partial \mathrm{Z}}\right)_{\mathrm{Z}=\mathrm{L}}, \mathrm{W} / \mathrm{m}^{2}
$$

In the literature (and in these experiments), good heat flux results are obtained when the partial derivative of front surface temperature with respect to time, i.e., the surface temperature response of the gage, matches the response of facility operating parameters. These parameters include transient gas temperature and pressure measurements.

\section{Seminfinite Heat Conduction Model}

For a semi-infinite model, it can be shown that the heat flux corresponding to a known surface temperature is ${ }^{8,10}$

$$
\dot{\mathrm{q}}_{\text {front }, \mathrm{si}}=\frac{\sqrt{\mathrm{k} \rho \mathrm{c}_{\mathrm{p}}}}{\sqrt{\pi}} \int_{0}^{\theta} \frac{\mathrm{dT}_{\mathrm{s}}(\tau) / \mathrm{d} \tau}{\sqrt{\theta-\tau}}
$$

The time rate of change of transient surface temperature, $\mathrm{dT}_{s}(\tau) / \mathrm{d} \tau$, is the surface temperature response of the gage. Heat flux expressed by Eq. (6) is evaluated over a short time period which starts when the test apparatus is turned on. The end of the time period corresponds to the time when the back surface of the gage starts to rise above the starting temperature. Thus at high heat flux conditions, this method is limited to heat flux evaluation only over a small initial portion of the start-up operating time of the apparatus. Where applicable, the results obtained with Eq. (6) are compared with the more practical and general inverse heat conduction and calculation procedure described herein.

\section{Design and Fabrication of Miniature Plug-Type Heat Flux Gage}

Long-established heat transfer and fluid flow concepts documented in Refs. 10-12 are used to conceive the dual active surface heat flux gage geometry shown in Figs. 1 and 2. As shown in Fig. 1, the back surface of the gage is cooled. The impingement cooling medium may be either air or water. This cooling allows the gage to survive when the gas temperature is much higher than the melting point of the gage material. An example of such an application is the measurement of heat flux in the NASA Ames Hypersonic Arc Jet Facility. Efficient impingement cooling of the gage is needed in this facility because the calculated gas temperature may be as high as $2300 \mathrm{~K}$, whereas the gage material must be cooled to $1250 \mathrm{~K}$. The gage material loses much of its strength at temperature above $1250 \mathrm{~K}$.

A small geometrical adjustment to this design (not shown) provides for a thermal insulating air space between the back of the post and the cover. This augmented design is called herein a "single active surface heat flux gage." This gage was designed to measure transient heat flux on one surface of an airfoil subjected to gas temperatures of $1150 \mathrm{~K}$ in a turbine blade tester (TBT). The thermally insulating space between the back of the post and the cover allows more energy to flow into the front active surface where the heat flux measurement of interest is to be made. This air space thermally insulates the back surface of the thermoplug from the cover. This is advantageous because then the temperature will usually decrease from the front to the back of the thermoplug. This type of temperature profile is readily measured with the limited number of thermocouples which can be inserted within the small annulus machined into the gage body. Installation of the thermocouples is shown in Fig. 3. After the thermocouples are installed, a cover is welded over the annulus and sheathed thermocouple wire which lies in a slot machined into the airfoil material. This cover is welded flush with 
the airfoil surface contour. The gage and airfoil were conduction-cooled through the base of the blade and through a cooled blade holder mounted in the TBT.

The heat flux sensing element for both these gage designs is a cylindrical post (Fig. 1 and 2). This post is formed in a specimen material by electrical discharge machining (EDM) procedures. The post diametertypically ranges from 0.080 to $0.150 \mathrm{~cm}$. The thermoplug length, $\mathrm{L}$, (Fig. 1) includes the front wall thickness plus the post length plus the cover thickness. The thermoplug length is typically 0.100 to $0.200 \mathrm{~cm}$. The annulus is typically 0.080 to $0.100 \mathrm{~cm}$ wide. The wall thickness may be 0.050 to $0.100 \mathrm{~cm}$ and the cover is nominally about $0.04 \mathrm{~cm}$ thick.

Electrical discharge machining of the post and annulus proceeds from the back of the material. Therefore, the front surface is not disturbed. That is, surface characteristics such as roughness and thermal radiation optical properties are not changed during the EDM process. A second advantage is that the post is an integral part of the gage material and therefore there is no seam to cause unwanted temperature disruptions in the vicinity of the temperature measurements. As discussed previously, a seam can cause a discontinuity in surface temperature which, in turn, can lead to noisy thermocouple signals and incomprehensible heat flux measurements. ${ }^{1}$ Another advantage is that, unlike circular foil gages where heat flux is measured across the gage surface, heat flux in the plug-type gages is measured in the physical direction of normal heat conduction through the wall.

Commercial sheathed wire thermocouple assemblies with diameter equal to $0.025 \mathrm{~cm}$ are used for temperature measurement. A length of 2 to $10 \mathrm{~cm}$ of sheathing is stripped to exposed bare Chromel or Alumel thermoelement wire which has a diameter of $0.0038 \mathrm{~cm}$. The ends of the bare wires are welded along the length of the post to form hot junctions. The location of the thermocouples on the post is measured with a toolmakers' microscope. The bare wires are routed through the annulus to the rear of the gage as shown in Figs. 1 and 2. Since the wires are positioned inside the gage, they are protected from erosion and corrosion by the external environment. More details of gage fabrication are documented in Refs. 5 and 6.

\section{Design Validation}

All gage designs were checked for their ability to accurately measure heat flux in a laboratory arc lamp calibrator. These calibrations were performed before and after the gages had been run in other facilities. The checks consisted of comparing gage output with transient and steady-state heat flux measurements made with com- mercial, water-cooled circular foil reference gages. The checks were made at $1,2,3,4,5$ and $6 \mathrm{MW} / \mathrm{m}^{2}$ of radiative lamp output. To do this, it is necessary to cover the surfaces of the plug-type gages with a high temperature black paint. This black paint has same optical properties as the surfaces of the circular foil reference gages. Plug-type gage designs were considered acceptable when their steadystate outputs compared with circular foil heat flux gage output within an error band of \pm 20 percent. When applicable, heat flux calculated with the semi-infinite heat conduction model (Eq. (6)) checked within \pm 10 percent of plug-gage output.

\section{$\underline{\text { Results and Discession }}$}

\section{Single Active Surface Plug-type Heat Flux Gage}

Single active surface gages were electrical discharge machined into SSME blade airfoils and tested in a groundbased turbine blade tester (TBT) at NASA George C. Marshall Space Flight Center. ${ }^{4}$ The airfoil material was MAR-M-246 which was hafnium modified and directionally solidified. Transient heat flux and surface temperatures were obtained on the suction (convex) and pressure (concave) surfaces of three solid SSME blade airfoils. A gage for measuring heat flux on the suction surface of an airfoil is shown in Fig. 3. Three gages were installed in each of three airfoils, checked in the calibrator and then installed in the ground-based TBT (Fig. 4). (The black paint used during arc lamp calibration was removed for these tests.) These blades do not rotate. Time resolved heat flux and surface temperatures were obtained on an airfoil pressure surface at mid-span and midchord, on another airfoil at mid-span at the throat region, and on a third airfoil on the suction surface midspan and midchord region. The TBT was operated through $2-1 / 2$ cycles for a total test time of $48 \mathrm{~s}$. Figure 5 shows gas and thermoplug temperatures. For clarity, the estimated surface temperatures are not shown in Fig. 5. Figure 6 shows surface temperature and absorbed surface heat flux data taken during one cycle of the TBT testing.

The estimated surface temperature, absorbed surface heat flux estimated on the three airfoils, gas pressure and gage surface temperature data were time resolved as valves controlling hydrogen and oxygen propellant flow were manipulated to simulate startup and shutdown of an actual SSME engine. This demonstrates that the gages are fully responsive to changes in SSME turbopump conditions.

The time-resolved heat flux data shown in Fig. 6 were cyclically repeatable within 5 percent on all three blades. These results were achieved even though there were large 
temperature gradients along the airfoil and gage surfaces. Transient temperatures varied from 150 to $1200 \mathrm{~K}$ in time intervals of $3 \mathrm{~s}$. During this time interval, gas pressures varied from 0.6 to $14 \mathrm{MPa}$ and heat fluxes varied from 0 to $21 \mathrm{MW} / \mathrm{m}^{2}$. No deleterious effects such as material cracking or loss of measurement accuracy were noted. When applicable (during startup of each cycle), these heat flux results were checked with Eq. (6). Even though temperature differences from the surface of the gage to the surrounding metal material surface were as high as $60 \mathrm{~K}$, agreement with Eq. (6) was within \pm 10 percent.

Dual Active Surface Plug-Type Heat Flux Gage Probe

The dual active surface heat flux gage probe concept is based on the design of the single active surface gages. The single active surface gages were invented for direct sensor fabrication into most metal materials. The probe concept extends the applicability these gages to surface measurements on material walls where direct sensor fabrication is not practical. For instance, the probe can be inserted through nonmetallic materials for surface heat flux measurement.

The probe was fabricated by attaching a dual-active surface heat flux gage (Figs. 1 and 2) to an air-cooled stem (Fig. 7). The gage was fabricated from Inconel alloy 700 and the stem from stainless steel 304. Continuous transient and steady-state absorbed surface heat fluxes and temperatures were measured with this probe-gage. ${ }^{7}$ The back of the gage was impingement-cooled with air flowing through the hollow stem. The probe-gage was tested in the ground-based NASA Ames Research Center 2 X 9 turbulent flow duct facility (Fig. 8). ${ }^{7}$ Heat flux is generated in the facility with a Huels arc-heater. The duct is formed into a rectangular cross-section and one wall of the duct is fabricated from $2.54 \mathrm{~cm}$ thick rigid surface thermal insulation material mounted on an aluminum plate. To measure heat flux, the probe was inserted through the plate and insulating materials such that the front of the gage was located flush with the hot gas-side insulation surface. The front of the gage was roughened to simulate the roughness of the insulation surface. Also, the front of the gage was covered with a high temperature black paint. The optical properties of the paint matched the optical properties of the insulation material surface and also matched the optical properties of the surfaces of six water-cooled circular-foil reference calorimeters. The reference calorimeters were mounted in a water-cooled metal duct wall opposite the probe-gage.

Correspondence of transient and steady heat fluxes measured with the six reference calorimeters and the probe-gage was generally within a satisfactory \pm 10 percent (Fig. 9). The plug-type gage transient heat flux values and gage surface temperature were time resolved with transient facility gas pressure and gas temperature operating conditions. The time rate of change of measured surface temperature of the insulation surrounding the gage also correlated with these changing parameters. The insulation surface temperature was measured with wire thermocouples. This good correspondence was achieved even though the much cooler probe caused a large measured surface temperature disruption of $1000 \mathrm{~K}$ between the metal gage body and insulation (Fig. 10). A seam or line of junction was formed between the gage body and insulation as the probe was inserted into position. These seams widened as the tests proceeded. Never-the-less, the thermocouple signals were very smooth. When applicable (during facility startup), these results were compared with estimates of heat flux using Eq. (6). Agreement was within \pm 10 percent, while temperature differences between gage and surrounding gage metal surface temperatures were as high as $300 \mathrm{~K}$. These favorable results demonstrate that the miniature plug-type heat flux gage design is an improvement over press-fitting (as discussed in the Introduction) instrumented cylindrical plugs into holes machined into material walls. ${ }^{1-2}$

\section{Concluding Remarks}

Heat flux gage design validation and calibration performed in a laboratory thermal radiation environment may not be a good predictor of how the same gage will measure convective heat flux or a mixture of convective and radiative heat flux in a facility. This research demonstrates that this difficulty may be minimized by designing a new type of heat flux gage which has an accuracy that is not diminished as it is transferred from laboratory to facility thermal environments. A key to such a design is to minimize the intrusive effect of temperature disruptions and temperature gradients along the gage surface. When compared to early research, the improved results obtained herein suggest that the miniature plug-type heat flux gages along with the improved analytical procedures described herein can minimize these effects. For best results, implementation of these gages should include design analysis and validation.

\section{$\underline{\text { References }}$}

1. Liebert, C.H., Hatch, J.E., and Grant, R.W.: "Application of Various Techniques for Determining Local Heat-Transfer Coefficients in a Rocket Engine From Transient Experimental Data."NASA TND277. April, 1960. 
2. Liebert, C.H. and Ehlers, R.C.: "Determination of Local Experimental Heat-Transfer Coefficients on Combustion Side of an Ammonia-Oxygen Rocket." NASA TN D-1048. Sept.1961.

3. Liebert, C.H.: "Measurement of Local High-Level, Transient Surface Heat Flux." NASA TP-2840. Sept. 1988.

4. Liebert, C.H.: "Miniature High Temperature PlugType Heat Flux Gages." NASA TN-105403. April,1992.

5. Liebert, C.H., and Koch, J. Jr.: "Plug-Type Heat Flux Gage." U.S. Patent No. 5,048,973. Sept 1991.

6. Liebert, C.H., and Koch, J. Jr., "Method of Producing a Plug-Type Heat Flux Gage." U.S. Patent No. 5086204. Feb. 1992.

7. Liebert, C.H.:" Dual Active Surface Heat Flux Gage Probe." NASA TM-106861. May,1995.
8. Schultz, D.L., and Jones, T.V.: "Heat Flux Measurements in Short-Duration Hypersonic Facilities. AGARD. Feb.1973.

9. Liebert, Curt H.: Miniature Convection Cooled PlugType Heat Flux Gages." NASA TM-106483. May, 1994.

10. Diller, T.E.: "Heat Flux Calibration-Progress Towards National Standards." Proceedings of the 41 st International Instrumentation Symposium. May, 1995.

11. Diller, T.E.: "Advances in Heat Flux Measurement. "Advances in Heat Transfer. Vol 23. 1993.

12. Westkaemper, J.C.: "On the Error in Plug-Type Calorimeters Caused by Surface-Temperature Mismatch." Journal of Aerospace Sciences. Nov. 1961. 


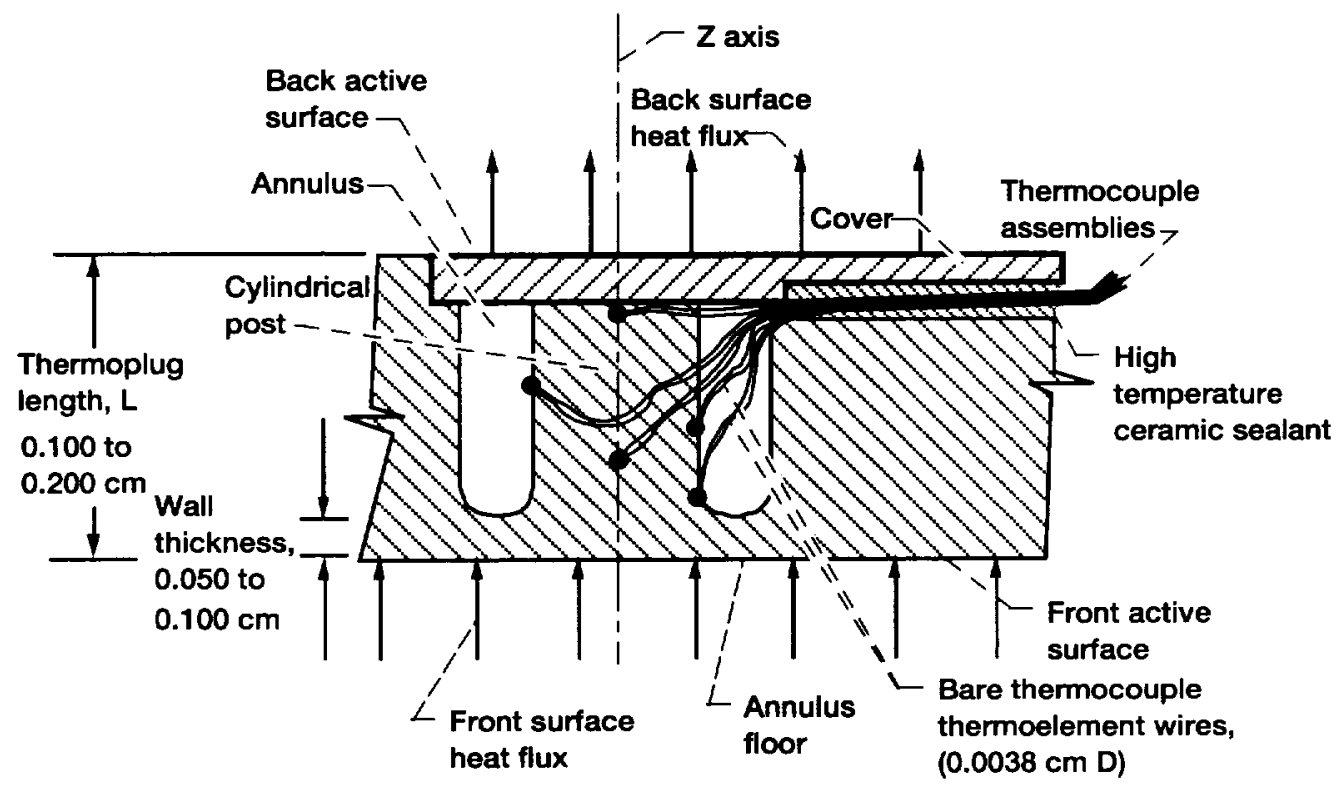

Figure 1.-Sideview of a typical miniature dual-active surface plug-type heat flux gauge body.

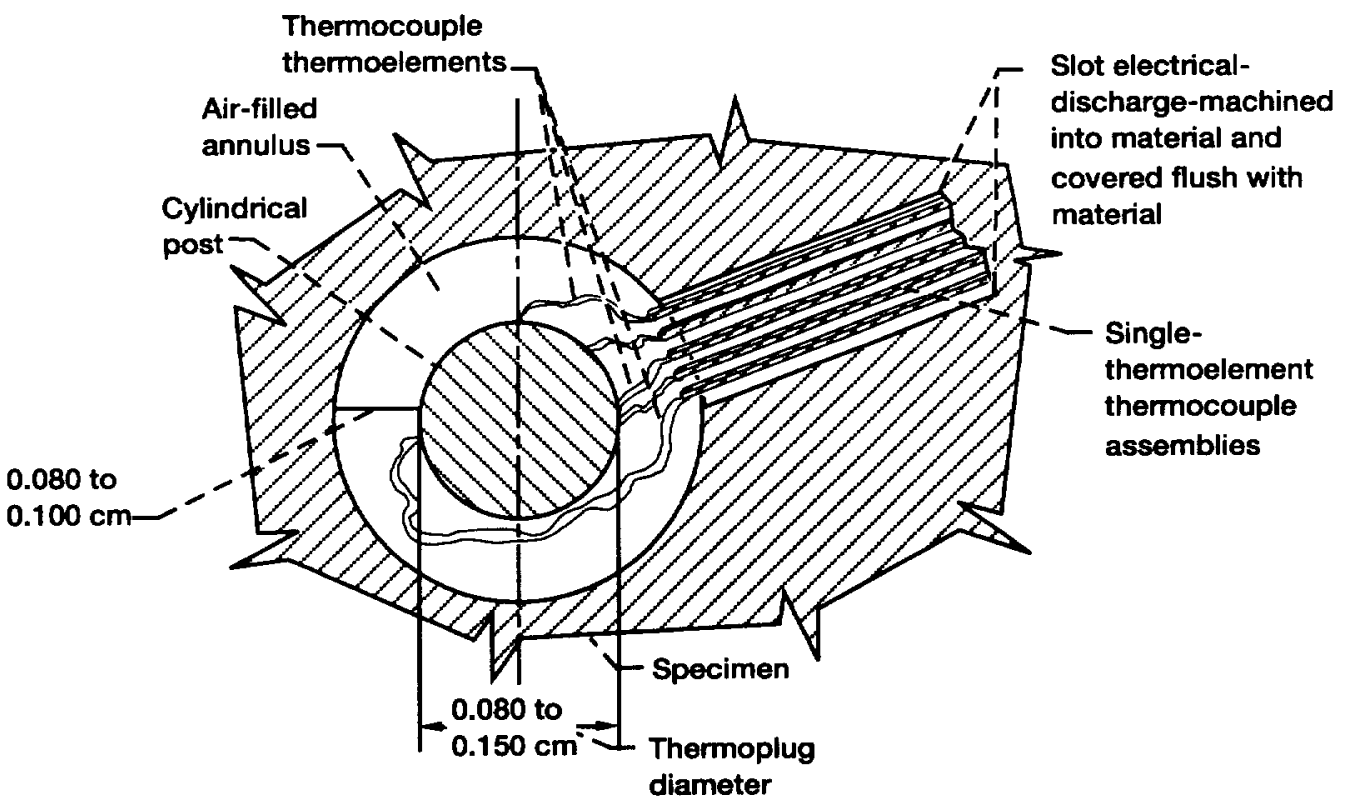

Figure 2.-Backview of a typical miniature dual active surface plug-type heat flux gauge body (cover removed). 


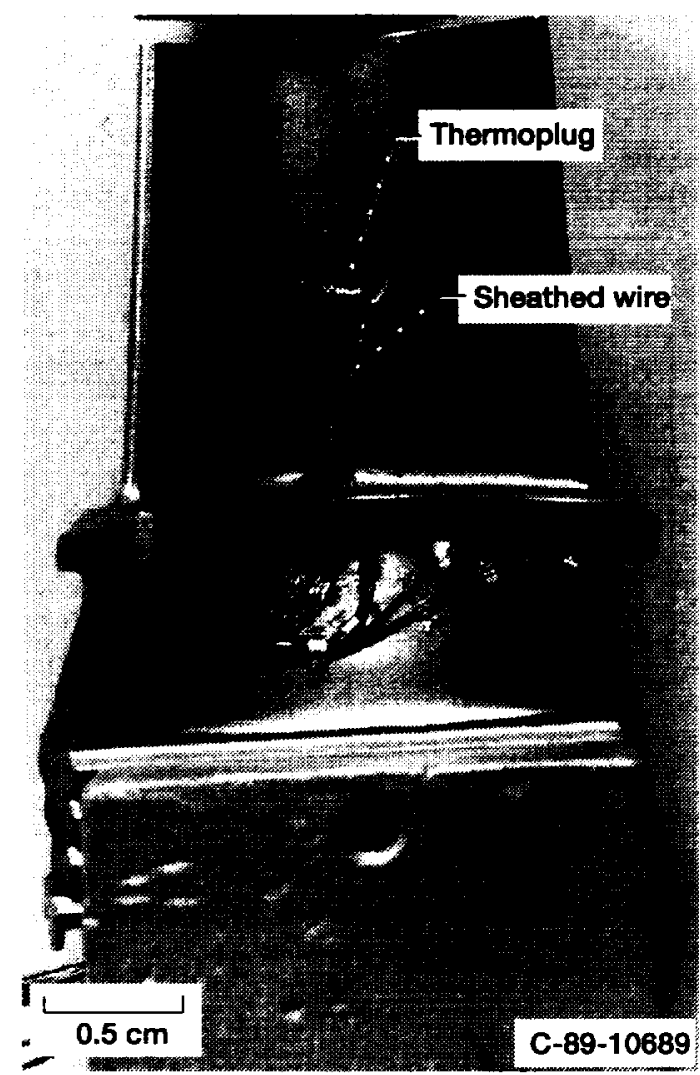

Figure 3.-Rear view of gage in SSME blade (with cover removed).

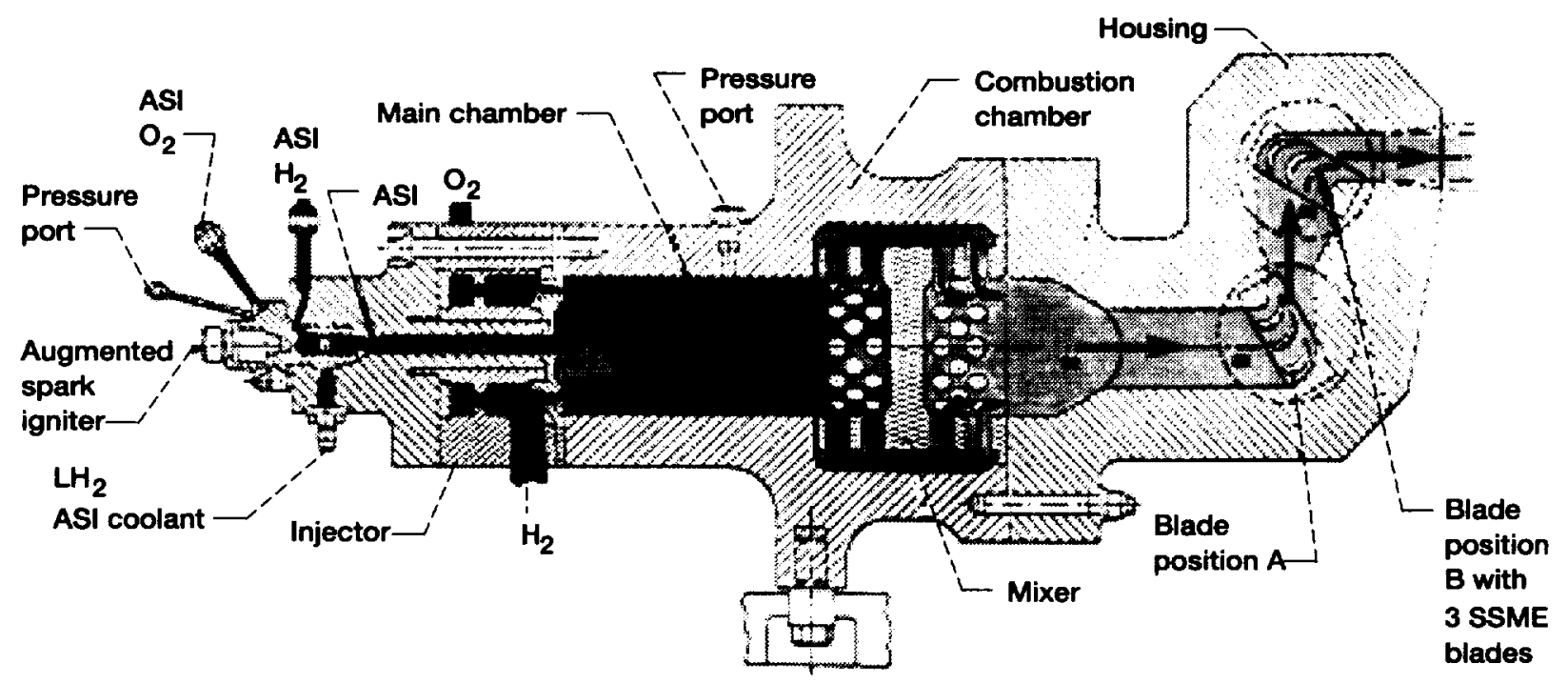

Figure 4.-Turbine blade thermal cycling tester (TBT). 

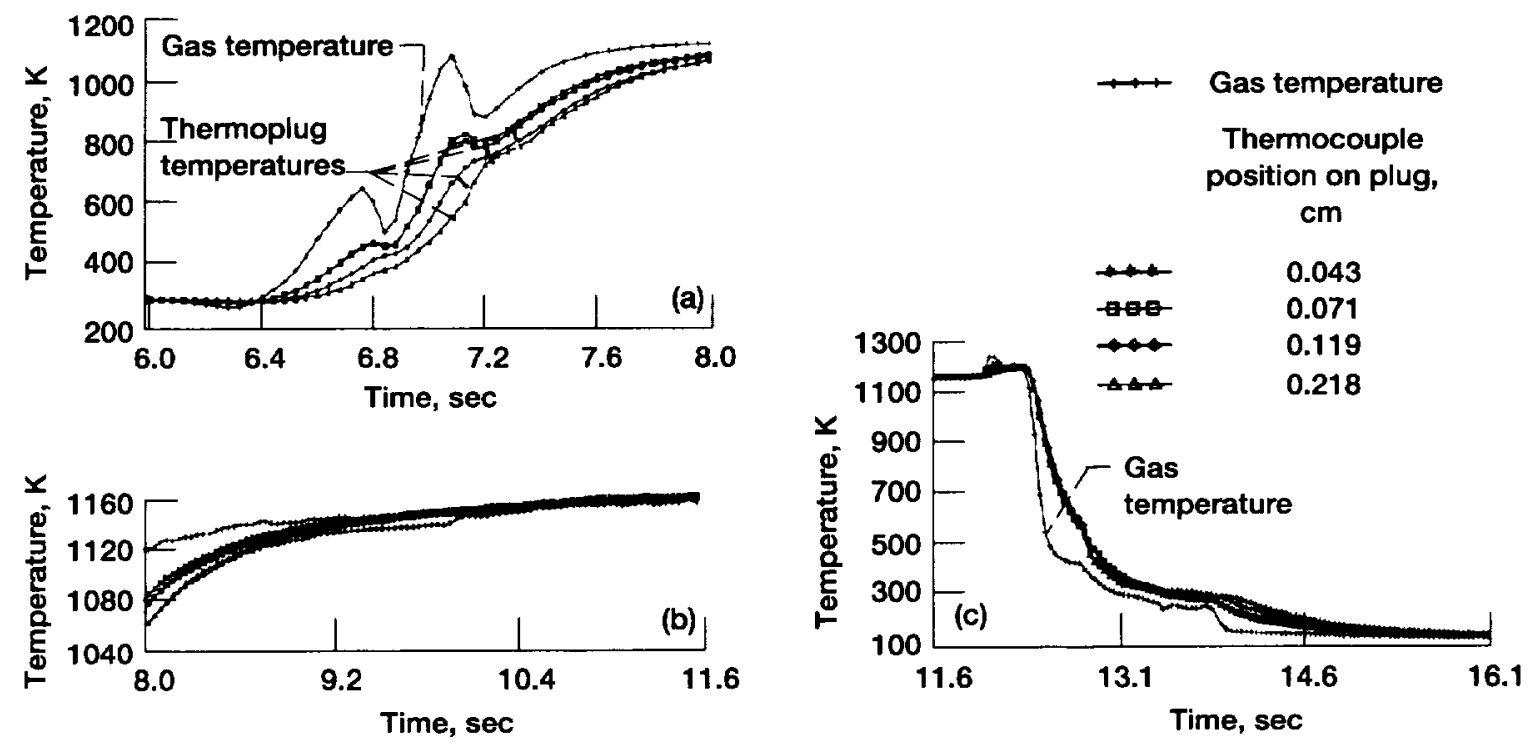

Figure 5.-Gas and gauge temperature history. (a) Startup, center blade. (b) Quasi steady, center blade. (c) Cooling, center blade.

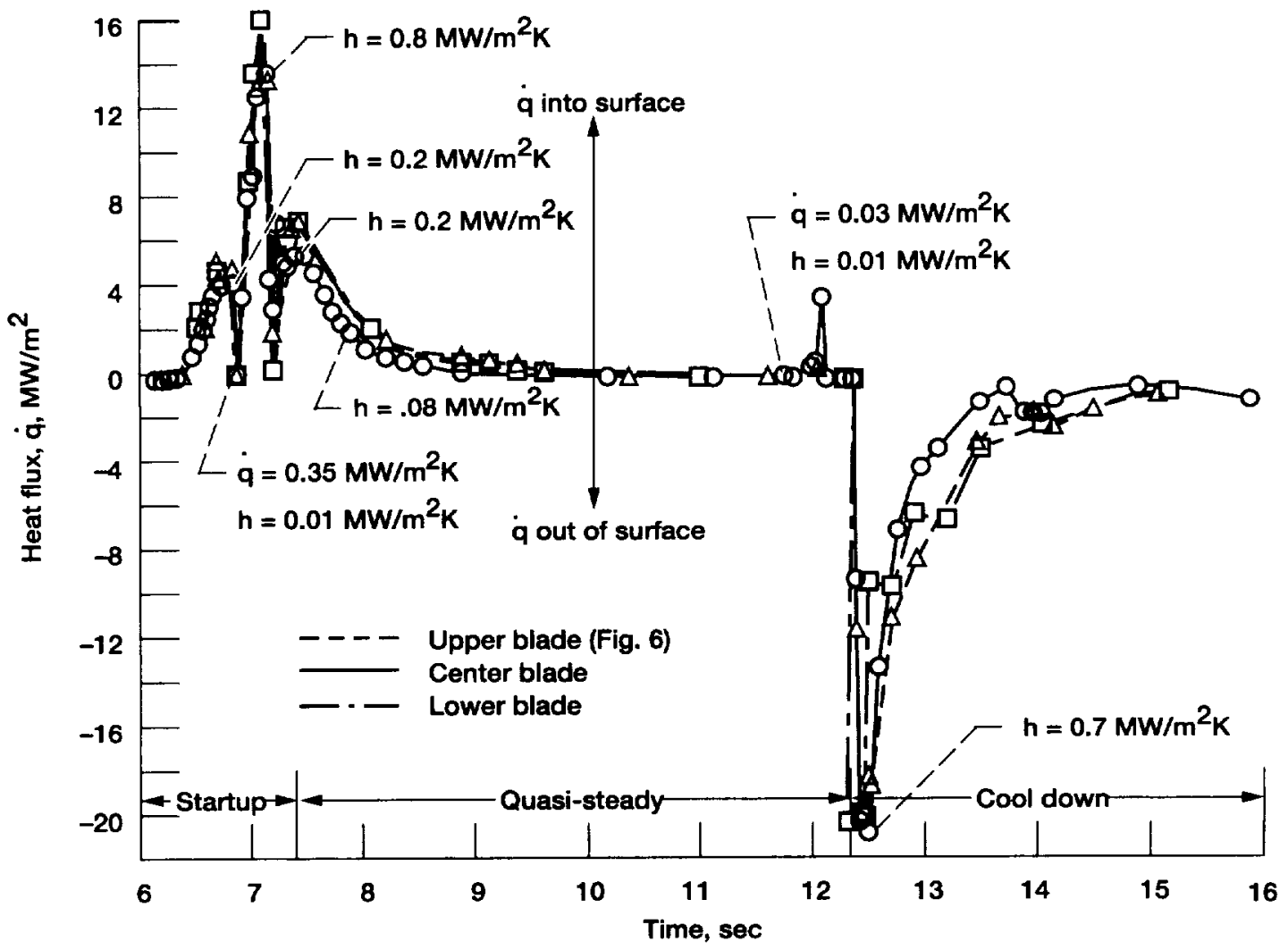

Figure 6.- Heat flux measured in turbine blade tester ( $h$ is heat transfer coefficient). 


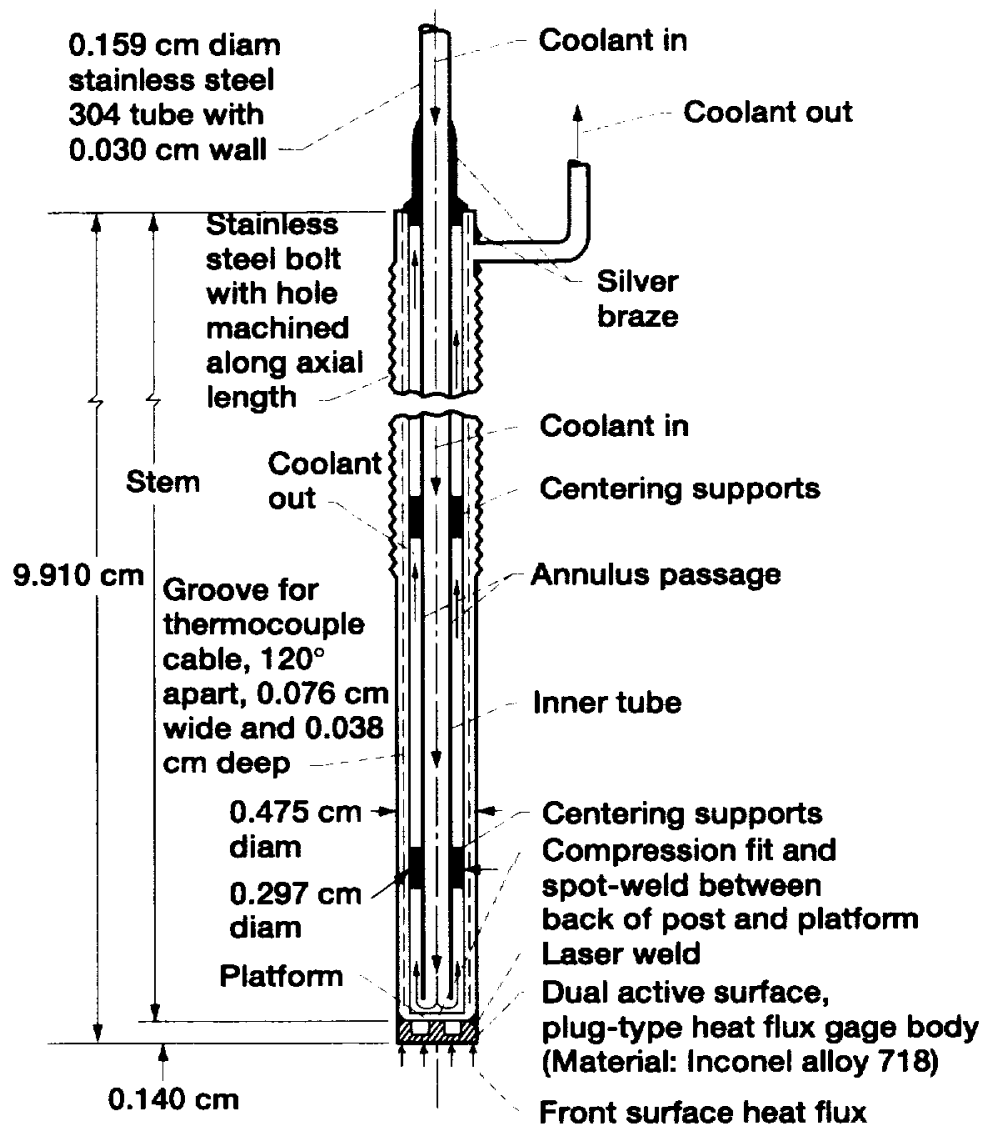

Figure 7.-Dual active surface heat flux gage probe assembly.

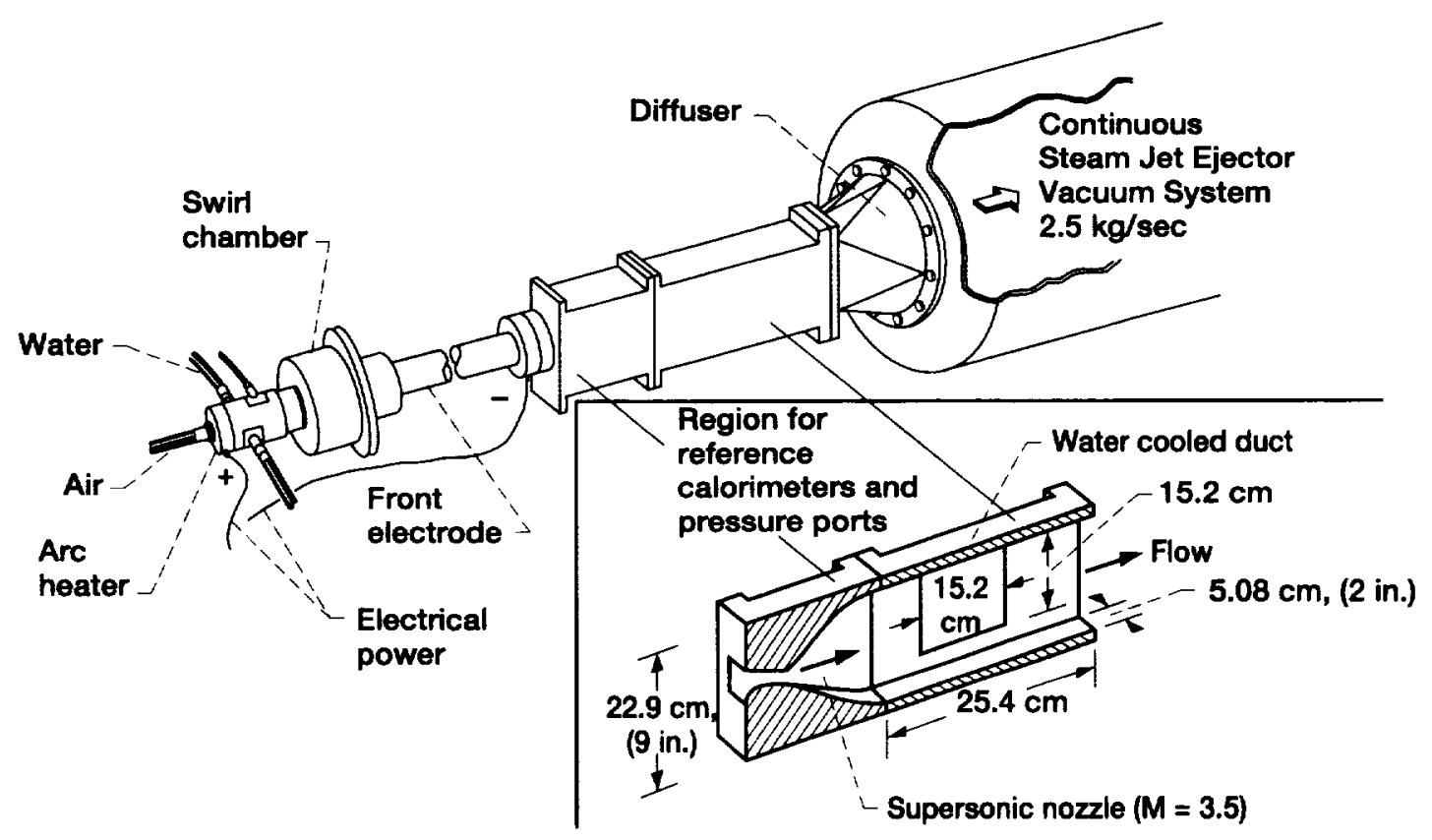

Figure 8.-AMES $2 \times 9$ Turbulent Flow Duct Facility. 


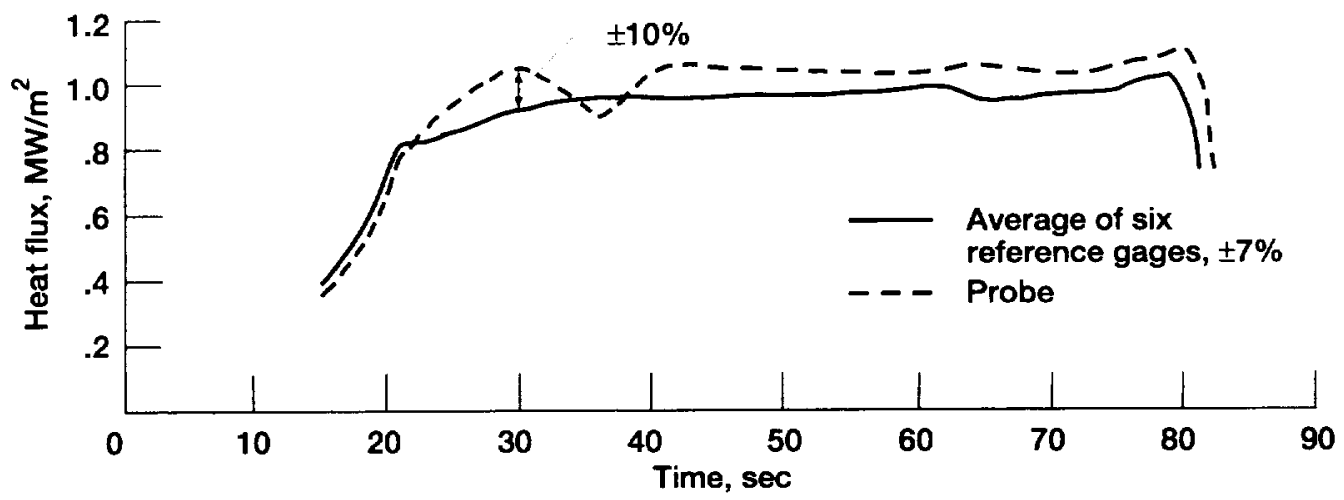

Figure 9.-Heat flux histories measured with reference gages and air-cooled probe.

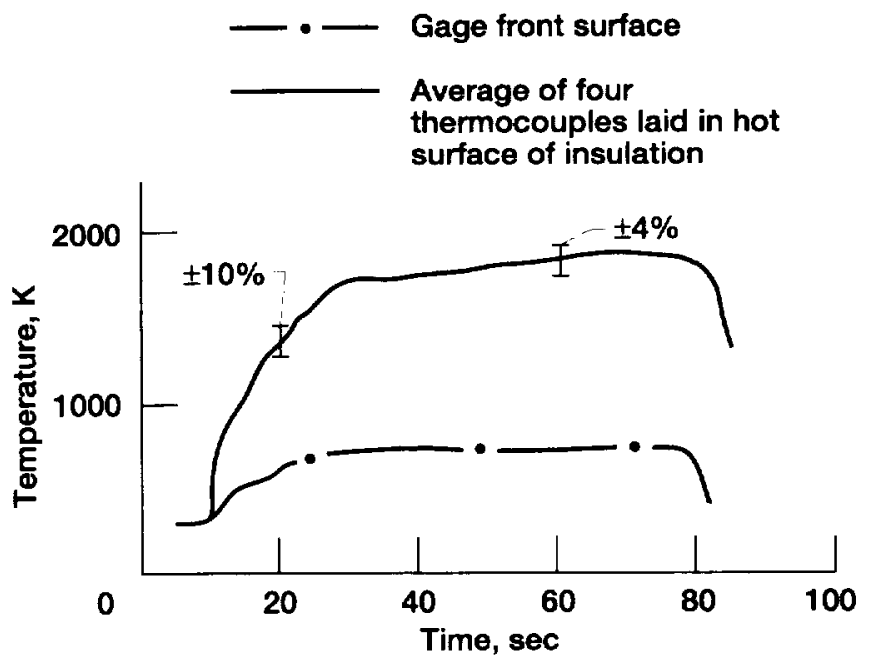

Figure 10.-Surface temperature histories of air-cooled probe. 
Public reporting burden for this collection of information is estimated to average 1 hour per response, including the time for reviewing instructions, searching existing data sources, gathering and maintaining the data needed, and completing and reviewing the collection of information. Send comments regarding this burden estimate or any other aspect of this collection of information, including suggestions for reducing this burden, to Washington Headquarters Services, Directorate for Information Operations and Reports, 1215 Jefferson Davis Highway. Suite 1204, Arlington, VA 22202-4302, and to the Office of Management and Budget, Paperwork Peduction Project (0704-0188), Washington, DC 20503.

\begin{tabular}{|l|c|c|c|}
\hline 1. AGENCY USE ONLY (Leave blank) & $\begin{array}{r}\text { 2. REPORT DATE } \\
\text { April } 1996\end{array}$ & $\begin{array}{r}\text { 3. REPORT TYPE AND DATES COVERED } \\
\text { Technical Memorandum }\end{array}$
\end{tabular}

\section{TITLE AND SUBTITLE}

An Investigation of the Compatibility of Radiation and Convection Heat Flux Measurements

\section{AUTHOR(S)}

Curt H. Liebert

\section{PERFORMING ORgANIZATION NAME(S) AND ADDRESS(ES)}

National Aeronautics and Space Administration

Lewis Research Center

Cleveland, Ohio 44135-3191

9. SPONSORINGMONITORING AGENCY NAME(S) AND ADDRESS(ES)

National Aeronautics and Space Administration

Washington, D.C. 20546-0001
5. FUNDING NUMBERS

WU-505-62-50

8. Performing organization REPORT NUMBER

E-10199

10. SPONSORINGMONITORING AGENCY REPORT NUMBER

NASA TM-107205

AIAA-96-2272

\section{SUPPLEMENTARY NOTES}

Prepared for the 19th Advanced Measurement and Ground Testing Technology Conference sponsored by the American Institute of Aeronautics and Astronautics, New Orleans, Louisiana, June 17-20, 1996. Responsible person, Curt H. Liebert, organization code 2510, (216) 433-6483.

12a. DISTRIBUTION/AVAILABILITY STATEMENT 12b. DISTRIBUTION CODE

Unclassified - Unlimited

Subject Category 35

This publication is available from the NASA Center for AeroSpace Information, (301) 621-0390.

13. ABSTRACT (Maximum 200 words)

A method for determining time-resolved absorbed surface heat flux and surface temperature in radiation and convection environments is described. The method is useful for verification of aerodynamic, heat transfer and durability models. A practical heat flux gage fabrication procedure and a simple one-dimensional inverse heat conduction model and calculation procedure are incorporated in this method. The model provides an estimate of the temperature and heat flux gradient in the direction of heat transfer through the gage. This paper discusses several successful time-resolved tests of this method in hostile convective heating and cooling environments.

\begin{tabular}{|c|c|}
\hline \multicolumn{2}{|l|}{$\begin{array}{l}\text { 14. SUBJECT TERMS } \\
\text { Heat flux; Temperature }\end{array}$} \\
\hline $\begin{array}{l}\text { 17. SECURITY CLASSIFICATION } \\
\text { OF REPORT } \\
\text { Unclassified }\end{array}$ & $\begin{array}{l}\text { 18. SECURITY CLASSIFICATION } \\
\text { OF THIS PAGE } \\
\text { Unclassified }\end{array}$ \\
\hline
\end{tabular}

\begin{tabular}{|c|c|}
\hline & $\begin{array}{c}\text { 15. NUMBER OF PAGES } \\
13\end{array}$ \\
\hline & $\begin{array}{r}\text { 16. PRICE CODE } \\
\text { A03 }\end{array}$ \\
\hline $\begin{array}{l}\text { 19. SECURITY CLASSIFICATION } \\
\text { OF ABSTRACT } \\
\text { Unclassified }\end{array}$ & 20. LIMITATION OF ABSTRACT \\
\hline
\end{tabular}




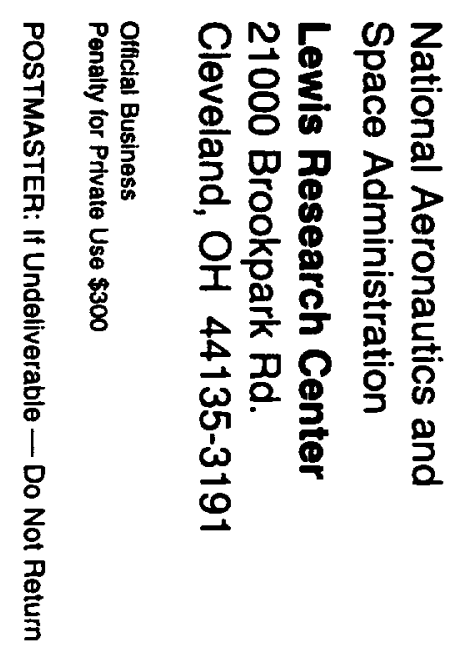

